\title{
Surgical Correction in Patients with Lumbar Degenerative Kyphosis Who Had Low Bone Mineral Density: An Analysis of 40 Patients with a Minimum Follow-Up of Two Years
}

\author{
Ki Tack Kim ${ }^{1}$, Chris Yin Wei Chan ${ }^{2}$, Sang Hun Lee ${ }^{1}$, Dae Seok Huh ${ }^{3}$, Eun Seok Son ${ }^{4}$ \\ ${ }^{I}$ Department of Orthopaedic Surgery, Spine Center, Kyung Hee University Hospital at Gangdong, Seoul, Korea \\ ${ }^{2}$ Department of Orthopaedic Surgery, Faculty of Medicine, University Malaya, Kuala Lumpur, Malaysia \\ ${ }^{3}$ Department of Orthopaedic Surgery, CMHospital, Seoul, Korea \\ ${ }^{4}$ Department of Orthopaedic Surgery, Dongsan Medical Center, Keimyung University College of Medicine, Daegu, Korea
}

\section{Study Design: Retrospective study.}

Purpose: To investigate influence of bone mineral density (BMD) on the surgical correction of lumbar degenerative kyphosis (LDK). Overview of Literature: No studies so far have reported the influence of BMD on the surgical correction of LDK.

Methods: Forty LDK patients with more than 2 years follow-up were studied. Pelvic incidence (PI), pelvic tilt, sacral slope, sagittal vertical axis (SVA), lumbar lordosis (LL), and thoracic kyphosis were measured preoperatively, immediate postoperatively and at final follow-up. Adverse outcomes: proximal adjacent fractures, sagittal decompensation, pseudoarthrosis, and cage subsidence were documented.

Results: There were 37 females and 3 males. Average age was $65.1 \pm 4.5$ years and mean follow-up was $34.2 \pm 16.7$ months. $42.5 \%$ were Takemitsu type 3 curves, 27.5\% type 2, 20.0\% type 4 and 10.0\% type 1. 37.5\% had osteopenia, 40.0\% osteoporosis and $22.5 \%$ had severe osteoporosis. SVA improved from $237.0 \pm 96.7 \mathrm{~mm}$ preoperatively to $45.3 \pm 41.8 \mathrm{~mm}$ postoperatively $(p=0.000)$. LL improved from $10.5^{\circ} \pm 14.7^{\circ}$ to $-40.6^{\circ} \pm 10.9^{\circ}$ postoperatively $(p=0.000)$. At final follow-up SVA deteriorated to $89.8 \pm 72.2 \mathrm{~mm}$ and $\mathrm{LL}$ to $34.7^{\circ} \pm 15.8^{\circ}(p=0.000)$. The association between late sagittal decompensation, pseudoarthrosis, or proximal adjacent fractures and osteoporosis was insignificant. The difference between immediate postoperative LL and PI (PIDiff) had a significant association with sagittal decompensation and pseudoarthrosis.

Conclusions: Osteoporosis did not influence the degree of correction, late sagittal decompensation, proximal adjacent fractures, and pseudoarthrosis in LDK. PIDiff had a significant association with sagittal decompensation and pseudoarthrosis.

Keywords: Lumbar degenerative kyphosis; Bone mineral density; Surgery; Outcome; Osteoporosis

\section{Introduction}

Kyphotic deformities of the spine alter the mechanics of the vertebral column as well as the muscles enveloping the vertebral column $[1,2]$. The clinical implication of this deformity is difficulty in maintaining sagittal balance

Received Mar 24, 2014; Revised May 1, 2014; Accepted May 13, 2014

Corresponding author: Chris Yin Wei Chan

Department of Orthopaedic Surgery, Faculty of Medicine, University Malaya,

50603, Lembah Pantai, Kuala Lumpur, Malaysia

Tel: +60128830301, Fax: +0379494642, E-mail: chrnat01@yahoo.com 
and horizontal gaze, and an increase in low back pain $[3,4]$. Many aetiologies can cause kyphotic deformity of the spine including ankylosing spondylitis, iatrogenic flatback syndrome, and post-traumatic or post-infectious kyphotic deformity. Lumbar degenerative kyphosis (LDK) is a unique entity that more commonly affects middleaged to elderly women in Asian countries, particularly Korea and Japan [5]. The clinical characteristics, epidemiology, and radiological findings of this disease were described and classified by Takemitsu et al. [5] in 1988. While the exact cause of this disease is only partially understood, this disease poses a specific challenge to the surgeons that differs from other flatback diseases. This disease affects older patients who frequently have concomitant poor bone quality [6,7]. It affects the mobile lumbar spine, which sometimes demonstrates instability; therefore, when surgical intervention is implicated, fixation to the sacrum or ilium is required. The combination of all these factors places the instrumentation construct under a tremendous force; thereby increasing the likelihood of failure. The effect of poor bone quality on pedicle screw purchase has been investigated [8-11]; but, to date none of the studies have specifically investigated the effect of osteoporosis on the outcome of surgical correction in LDK.

\section{Materials and Methods}

A total of 40 patients were included in this retrospective study. All of the patients were diagnosed with LDK based on clinical as well as radiological investigations. Patients presented with symptoms such as stooping, low back pain, and fatigability during prolonged walking with or without symptoms of spinal stenosis. Radiological findings included sagittal imbalance and lumbar spondylotic changes without fractures involving the lumbar spine. All of the patients included in the study had undergone bone mineral densitometry (BMD) measurements of the spine and hip by utilizing a dual energy X-ray absorptiometry (DEXA) scan performed within 6 months of the surgical intervention. Only patients with follow-up of more than two years were included in the study. To distinguish patients with LDK and concomitant osteoporotic fragility fractures from those with post-traumatic kyphosis, patients with fractures within the lumbar region contributing to kyphosis were excluded from the study.

Surgical intervention in these patients consisted of seg- mental pedicle screw insertion with or without supplementary iliac or iliosacral screws. All of the patients had undergone posterior release via multiple Smith Petersen osteotomies and anterior column support using either posterior lumbar interbody cages or anterior lumbar interbody cages. The need for performing additional osteotomies in the form of partial pedicle subtraction osteotomies, pedicle subtraction osteotomies or posterior vertebral column resection was assessed after the posterior release and based on intraoperative radiographs. The choice of the upper instrumented vertebra (UIV) depended on the type of curve. For Takemitsu type 4 curves, fusion was invariably extended to T10 or higher. For type 1 to 3 curves, the UIV depended on the apex of lumbar kyphosis. For kyphosis below L3, the UIV was L2; but when the apex was at L3, higher fusion was at L1 to T10. When a partial pedicle subtraction osteotomy was required, instrumentation was extended at least 2 levels above the osteotomy site; and when a pedicle subtraction osteotomy or posterior vertebral column resection was needed, instrumentation at 3 levels above the osteotomy level was performed. Postoperatively, a thoracolumbar support orthosis was prescribed for 3 months. Medication for osteoporosis treatment was commenced only after bony union was established.

\section{Radiographic analysis}

Anteroposterior as well as lateral $14 \times 36$ inch full-length spine radiographs of the 40 subjects standing with their arms on the clavicle position unsupported were obtained after 10 minutes of walking. The radiographs were taken with the hip joint being perpendicular to the cassette, and with the knee joint completely extended. Dynamic views of the lateral lumbar radiographs and lateral radiograph of the pelvis were also obtained. These radiographs were obtained preoperatively, 6 weeks postoperatively, as well as at the final follow-up. The digital images were archived using a digital archiving software (Infinitt, Seoul, Korea) that allowed for magnification of anatomical landmarks to increase the accuracy of measurements. A singe investigator performed all of the radiological measurements.

\section{Sagittal parameters}

Positive values for thoracic kyphosis and lumbar lordosis indicated kyphosis, whereas negative values indicated 
lordosis. Positive values for sagittal vertical axis (SVA) indicated the center of the $\mathrm{C} 7$ body was anterior to the posterior superior corner of the sacrum, whereas a negative value indicated otherwise. The spinopelvic parameters examined in this study included:

Thoracic kyphosis (TK): measured between the superior end plate of T5 and the inferior end plate of T12 using the Cobb method.

Lumbar lordosis (LL): measured between the superior end plate of the L1 vertebra to the superior end plate of the $S 1$ vertebra using the Cobb method.

Pelvic incidence (PI): defined as the angle between the perpendicular line from the sacral plate and the line connecting the midpoint of the sacral plate to the bicoxofemoral axis.

Sacral slope (SS): defined as the angle between the sacral plate and the horizontal plane.

Pelvic tilt (PT): defined as the angle between the line connecting the midpoint of the sacral plate to the bicoxofemoral axis and the vertical plane.

Sagittal vertical axis (SVA): defined as the horizontal distance between the posterior corner of the sacrum and the $\mathrm{C} 7$ plumb line.

The difference between the immediate postoperative lumbar lordosis and the pelvic incidence (PIDiff) was calculated from the above measurements.

In the follow-up radiographs, sagittal decompensation, proximal adjacent fracture, pseudoarthrosis, as well as cage subsidence were documented. Sagittal decompensation was diagnosed when during the final follow-up the SVA was $\geq 8 \mathrm{~cm}$ anterior to the posterior superior corner of the sacrum [12]. Pseudoarthrosis was diagnosed when the segmental motion was greater than $5^{\circ}$ on the dynamic views, the radiolucent line around the pedicle screw was thicker than $3 \mathrm{~mm}$, and/or implant failure.

\section{Diagnosis of osteoporosis}

The diagnosis of osteoporosis was established based on the World Health Organization guidelines utilizing $t$ scores obtained from DEXA scans of the hip and spine. Patients without fragility fractures who had $t$-scores $\geq-1.0$ standard deviation from the reference values were considered to be normal, patients without fragility fractures who had $t$-scores $<-1$ to $>-2.5$ were considered to have osteopenia, and patients without fragility fractures who had $t$-scores $\leq-2.5$ were considered to have osteoporo- sis. Patients with fragility fractures regardless of DEXA scan results were also diagnosed with osteoporosis, while patients with $t$-scores $\leq-2.5$ and presence of fragility fractures were categorized as having severe osteoporosis [13].

\section{Statistical analysis}

Statistical tests performed were the chi-square test, independent and paired $t$-test, and one-way analysis of variance (ANOVA) test in SPSS ver. 20.5 (IBM Co., Somers, NY, USA). Statistical significance was set at 0.05 .

\section{Results}

A total of 40 patients were included in the analysis. There were 37 (92.5\%) female and $3(7.5 \%)$ male patients. The average age of the study population was $65.1 \pm 4.5$ years. The mean follow-up duration was $34.2 \pm 16.7$ months. The majority of the cases were classified as Takemitsu type 3 curves (42.5\%), followed by type 2 (27.5\%), type 4 (20.0\%), and type $1(10.0 \%)$. Also, $37.5 \%$ of the patients had osteopenia, $40.0 \%$ of the patients had osteoporosis, and $22.5 \%$ of the patients had severe osteoporosis. Also, $27.5 \%$ of the patients underwent surgery via a posterior approach, whereas the majority $(72.5 \%)$ of patients underwent an anterior-posterior surgery. When a posterior approach was performed in addition to Smith Petersen osteotomies, $36.4 \%$ of patients required a pedicle subtraction osteotomy or a posterior vertebral column resection. When an anterior-posterior approach was performed, $17.2 \%$ of patients needed additional osteotomies in the form of partial pedicle subtraction osteotomies, pedicle subtraction osteotomies, or posterior vertebral column resection (Fig. 1). The average number of fusion levels was $6.9 \pm 1.7$. Table 1 depicts the demographic data; classification; and preoperative, postoperative, and final followup sagittal parameters in the 40 patients included in this study.

For the following analysis, patients were stratified according to the degree of osteoporosis. Table 2 depicts the preoperative parameters of the study population. There were no statistically significant differences in the demographics, curve types, as well as severity of deformities in terms of SVA, LL, and TK. The PI was also similar among the 3 patient groups. The BMD measurements correlated significantly with the severity of osteoporosis.

Postoperative improvements in the sagittal and pelvic 
Table 1. Data for study group depicting demographic data, classification, preoperative, postoperative and final follow-up sagittal parameters

\begin{tabular}{|c|c|c|c|c|c|c|c|c|c|c|c|c|c|c|}
\hline \multirow{2}{*}{ No. } & \multirow{2}{*}{ Sex } & \multirow{2}{*}{$\begin{array}{l}\text { Age } \\
\text { (yr) }\end{array}$} & \multirow{2}{*}{$\mathrm{TA}$} & \multirow{2}{*}{$\mathrm{PI}$} & \multirow{2}{*}{ BMD } & \multicolumn{3}{|c|}{ Preoperative } & \multicolumn{3}{|c|}{ Postoperative } & \multicolumn{3}{|c|}{ Final } \\
\hline & & & & & & SVA & $\overline{\mathrm{LL}}$ & $\overline{\mathrm{TK}}$ & SVA & $\overline{\mathrm{LL}}$ & $\overline{T K}$ & SVA & $\overline{\mathrm{LL}}$ & $\mathrm{TK}$ \\
\hline 1 & Female & 63 & 2 & 60.0 & -3.5 & 202.3 & 11.4 & -8.3 & 95.2 & -13.5 & 16.7 & 171.4 & -13.9 & 20.1 \\
\hline 2 & Male & 67 & 3 & 58.9 & -1.1 & 284.5 & 0.2 & 27.9 & 87.4 & -35.0 & 21.2 & 185.3 & -27.2 & 26.2 \\
\hline 3 & Female & 63 & 2 & 48.5 & -2.9 & 105.1 & 5.3 & -1.0 & 92.8 & -35.1 & 20.5 & 160.5 & -35.2 & 35.2 \\
\hline 4 & Female & 60 & 2 & 61.2 & -2.1 & 188.0 & -12.7 & -2.9 & 104.7 & -36.7 & 20.5 & 128.5 & -39.2 & 28.4 \\
\hline 5 & Female & 74 & 4 & 55.0 & -2.7 & 390.4 & 19.0 & 40.6 & 151.7 & -20.1 & 32.3 & 267.6 & -18.6 & 65.6 \\
\hline 6 & Female & 63 & 1 & 53.5 & -1.8 & 210.5 & -9.0 & 11.0 & 70.7 & -38.7 & 46.2 & 75.6 & -42.4 & 45.4 \\
\hline 7 & Female & 63 & 3 & 61.5 & -1.7 & 181.2 & 23.1 & -9.3 & 23.1 & -45.3 & 16.6 & 38.8 & -40.3 & 33.1 \\
\hline 8 & Female & 66 & 3 & 54.5 & -1.8 & 294.5 & 25.9 & 0.8 & 46.9 & -40.6 & 23.0 & 76.7 & -34.3 & 27.1 \\
\hline 9 & Female & 62 & 3 & 62.9 & -4.4 & 269.9 & 34.4 & 10.3 & -26.2 & -39.6 & 15.9 & 215.2 & 5.5 & 45.0 \\
\hline 10 & Female & 58 & 4 & 63.3 & -4.5 & 342.4 & 26.6 & 48.3 & 69.9 & -35.6 & 49.4 & 78.9 & -38.1 & 65.0 \\
\hline 11 & Female & 66 & 3 & 62.6 & -6.6 & 273.0 & 26.6 & -6.1 & 16.7 & -27.7 & 14.6 & 182.9 & -15.4 & 26.9 \\
\hline 12 & Female & 56 & 3 & 45.9 & -4.3 & 72.0 & 15.5 & 10.5 & 13.8 & -28.8 & 12.7 & 93.9 & -11.8 & 28.7 \\
\hline 13 & Female & 75 & 4 & 58.3 & -3.5 & 286.8 & 22.8 & 52.4 & 119.7 & -31.5 & 38.8 & 250.8 & -16.4 & 59.9 \\
\hline 14 & Female & 67 & 3 & 66.1 & -4.4 & 91.8 & -14.3 & 8.8 & 49.2 & -35.1 & 22.1 & 74.3 & -36.8 & 16.0 \\
\hline 15 & Female & 66 & 3 & 49.9 & -1.3 & 210.3 & 0.5 & 15.7 & 65.7 & -26.8 & 26.8 & 56.7 & -2.0 & 6.9 \\
\hline 16 & Female & 65 & 4 & 54.9 & -2.6 & 377.4 & 40.8 & 53.9 & 45.9 & -49.6 & 34.8 & 169.2 & -41.8 & 44.0 \\
\hline 17 & Female & 68 & 3 & 62.9 & -3.4 & 248.4 & 4.5 & 2.7 & 138.0 & -39.1 & 19.6 & 160.5 & -36.1 & 18.0 \\
\hline 18 & Female & 65 & 2 & 59.9 & -1.7 & 174.3 & -8.6 & 8.6 & 72.0 & -29.1 & 23.5 & 175.8 & -19.9 & 31.3 \\
\hline 19 & Female & 68 & 4 & 62.5 & -3.0 & 367.8 & 24.0 & 26.1 & 43.5 & -41.9 & 28.9 & 129.6 & -24.4 & 37.4 \\
\hline 20 & Female & 73 & 2 & 69.8 & -3.6 & 156.3 & -3.6 & 9.8 & 36.6 & -32.3 & 7.3 & 118.8 & -14.2 & 1.5 \\
\hline 21 & Male & 65 & 4 & 59.1 & -1.5 & 372.3 & 33.0 & 58.5 & 7.2 & -59.4 & 20.1 & 41.7 & -46.7 & 38.1 \\
\hline 22 & Female & 71 & 3 & 63.8 & -2.7 & 239.1 & 3.8 & 1.3 & 56.4 & -32.8 & 22.3 & 67.5 & -23.6 & 30.5 \\
\hline 23 & Female & 65 & 1 & 50.4 & -4.1 & 70.6 & -12.3 & 5.7 & 39.6 & -26.1 & 26.7 & 45.9 & -27.4 & 25.1 \\
\hline 24 & Female & 72 & 3 & 63.5 & -3.7 & 258.9 & -1.5 & 19.7 & 29.4 & -45.1 & 23.4 & 9.6 & -43.0 & 13.9 \\
\hline 25 & Female & 60 & 3 & 55.0 & -4.5 & 238.8 & 22.6 & 5.1 & 7.0 & -46.4 & 18.1 & -4.0 & -45.7 & 29.4 \\
\hline 26 & Female & 60 & 1 & 61.5 & -1.6 & 22.2 & 16.9 & 3.4 & 34.5 & -44.6 & 25.4 & 0.0 & -44.8 & 31.8 \\
\hline 27 & Female & 62 & 2 & 65.8 & -1.5 & 246.6 & 8.9 & 15.6 & 50.4 & -34.6 & 30.8 & 132.9 & -21.6 & 18.2 \\
\hline 28 & Female & 63 & 3 & 57.9 & -2.4 & 330.5 & 26.4 & 5.7 & 0.0 & -49.9 & 26.7 & 0.0 & -48.4 & 32.7 \\
\hline 29 & Female & 67 & 4 & 50.7 & -3.1 & 416.1 & 24.2 & 27.2 & -19.5 & -48.4 & 31.5 & 42.9 & -49.5 & 35.1 \\
\hline 30 & Female & 68 & 3 & 64.9 & -3.3 & 276.9 & -9.2 & 3.9 & 42.3 & -45.9 & 19.6 & 31.8 & -47.3 & 27.2 \\
\hline 31 & Female & 64 & 2 & 48.4 & -2.7 & 72.9 & 7.2 & 27.2 & -20.7 & -49.5 & 33.2 & 4.2 & -58.8 & 60.7 \\
\hline 32 & Female & 65 & 4 & 67.4 & -2.8 & 324.3 & 5.2 & 21.1 & 46.2 & -39.9 & 37.3 & 74.3 & -42.6 & 37.7 \\
\hline 33 & Female & 67 & 1 & 71.3 & -3.1 & 155.4 & 28.9 & 3.0 & 39.0 & -61.2 & 19.6 & 14.6 & -62.3 & 33.9 \\
\hline 34 & Male & 54 & 2 & 58.5 & -1.4 & 233.1 & 9.7 & 5.2 & 4.8 & -51.1 & 29.3 & 31.0 & -46.1 & 30.6 \\
\hline 35 & Female & 68 & 3 & 61.4 & -2.8 & 302.4 & 0.2 & 50.2 & 80.7 & -51.1 & 36.6 & 33.9 & -44.2 & 34.4 \\
\hline 36 & Female & 66 & 2 & 54.6 & -3.4 & 336.6 & 11.8 & 1.2 & 9.0 & -50.9 & 15.8 & 25.0 & -47.3 & 22.4 \\
\hline 37 & Female & 66 & 3 & 54.8 & -2.4 & 215.4 & 3.0 & 11.5 & 28.2 & -41.9 & 36.5 & 92.7 & -36.7 & 38.8 \\
\hline 38 & Female & 66 & 2 & 46.4 & -3.8 & 226.5 & -9.8 & 0.7 & 40.5 & -44.8 & 11.5 & 56.7 & -38.4 & 21.0 \\
\hline 39 & Female & 67 & 3 & 54.8 & -1.6 & 257.7 & 9.3 & 15.0 & 36.9 & -57.9 & 31.4 & 34.8 & -55.5 & 36.6 \\
\hline 40 & Female & 60 & 2 & 57.5 & -1.4 & 156.0 & 7.6 & 5.8 & -18.6 & -60.6 & 16.7 & 46.1 & -57.2 & 33.9 \\
\hline
\end{tabular}

TA, Takemitsu classification; PI, pelvic incidence; BMD, bone mineral density; SVA, sagittal vertical axis measured in mms; LL, lumbar lordosis; TK, thoracic kyphosis; Final, at final follow-up. 

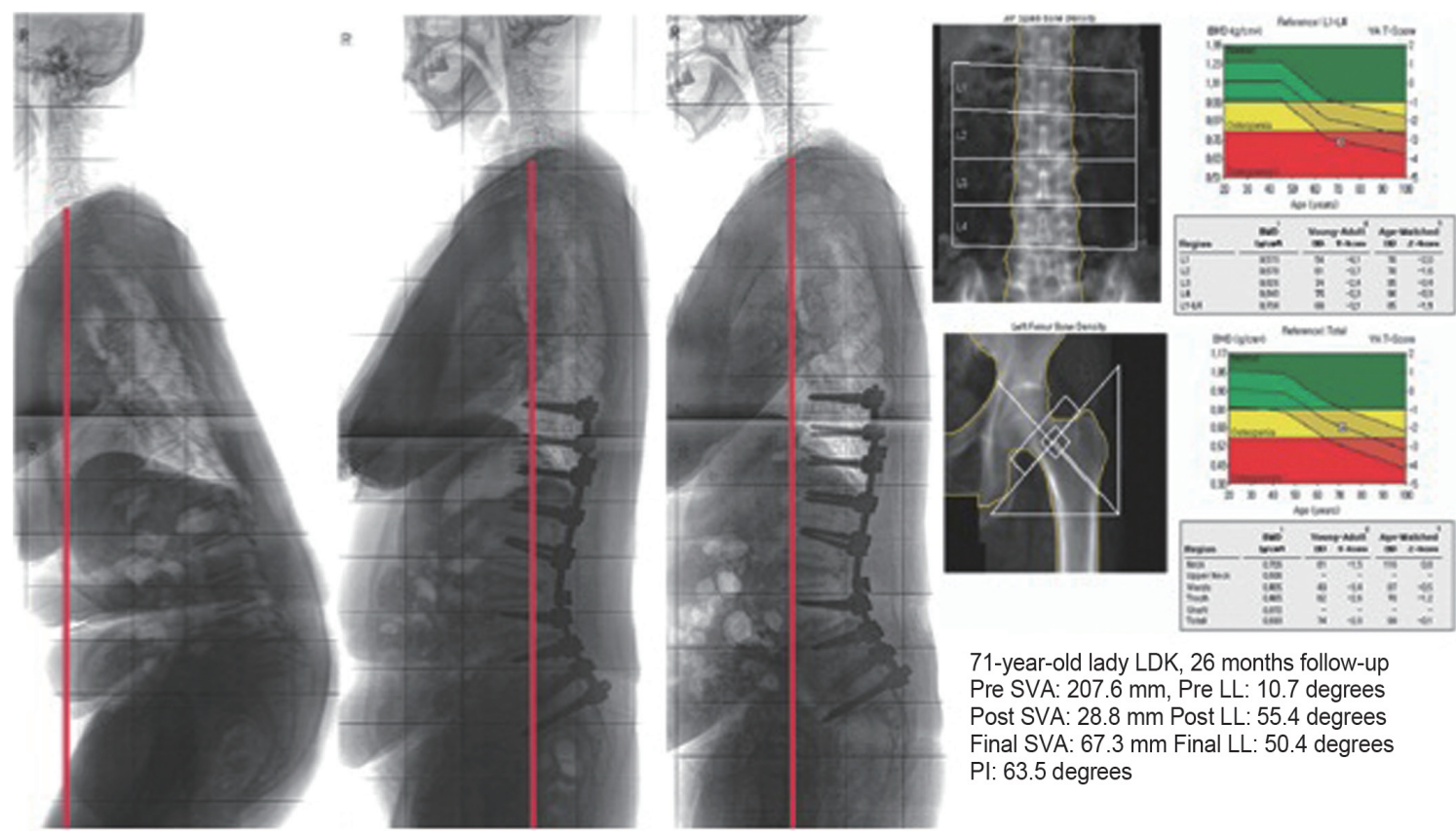

71-year-old lady LDK, 26 months follow-up Pre SVA: $207.6 \mathrm{~mm}$, Pre LL: 10.7 degrees Post SVA: $28.8 \mathrm{~mm}$ Post LL: 55.4 degrees Final SVA: $67.3 \mathrm{~mm}$ Final LL: 50.4 degrees PI: 63.5 degrees

Fig. 1. Case example of 71-year-old lady with osteoporosis who underwent posterior spinal fusion from T10 to ilium, ALIF at L4-5, L5-S1, and partial pedicle subtraction at L3. ALIF, anterior lumbar interbody fusion; LDK, lumbar degenerative kyphosis; SVA, sagittal vertical axis; LL, lumbar lordosis.

Table 2. Preoperative parameters of patients stratified to osteoporosis classification

\begin{tabular}{|c|c|c|c|c|}
\hline Parameter & Osteopenia & Osteoporosis & Severe osteoporosis & $p$-value \\
\hline No. of patients & 15 & 16 & 9 & $>0.05$ \\
\hline Age (yr) & $63.1 \pm 3.5$ & $66.0 \pm 5.2$ & $66.8 \pm 3.6$ & $>0.05$ \\
\hline Gender & & & & $>0.05$ \\
\hline Male & 3 & 0 & 0 & \\
\hline Female & 12 & 16 & 9 & \\
\hline Takemitsu clssificaton & & & & $>0.05$ \\
\hline I & 2 & 0 & 2 & \\
\hline$\|$ & 5 & 5 & 1 & \\
\hline III & 7 & 6 & 4 & \\
\hline IV & 1 & 5 & 2 & \\
\hline BMD & $-1.7 \pm 0.4$ & $-3.4 \pm 0.6$ & $-3.9 \pm 1.1$ & 0.000 \\
\hline Pelvic incidence $\left({ }^{\circ}\right)$ & $57.9 \pm 4.0$ & $58.6 \pm 7.4$ & $59.3 \pm 7.9$ & $>0.05$ \\
\hline Pre-SVA (mm) & $225.1 \pm 82.4$ & $263.6 \pm 95.4$ & $209.4 \pm 118.6$ & $>0.05$ \\
\hline Pre-LL $\left(^{\circ}\right)$ & $8.9 \pm 13.9$ & $10.1 \pm 14.0$ & $13.5 \pm 18.0$ & $>0.05$ \\
\hline Pre-TK $\left(^{\circ}\right)$ & $11.5 \pm 15.7$ & $17.7 \pm 20.4$ & $14.7 \pm 18.0$ & $>0.05$ \\
\hline Pre-PT $\left({ }^{\circ}\right)$ & $35.4 \pm 11.6$ & $41.9 \pm 8.4$ & $41.1 \pm 8.1$ & $>0.05$ \\
\hline Pre-SS $\left(^{\circ}\right)$ & $22.1 \pm 10.4$ & $16.6 \pm 10.4$ & $18.5 \pm 8.6$ & $>0.05$ \\
\hline
\end{tabular}

BMD, bone mineral density; SVA, sagittal vertical axis; LL, lumbar lordosis; TK, thoracic kyphosis; PT, pelvic tilt; SS, sacral slope.

parameters were significant as shown in Table 3 . The SVA improved from a preoperative value of $237.0 \pm 96.7$ $\mathrm{mm}$ to a postoperative value of $45.3 \pm 41.8 \mathrm{~mm}(p=0.000$, paired $t$-test). The LL also improved significantly from 
Table 3. Comparison between preoperative, immediate postoperative and final follow-up sagittal parameters

\begin{tabular}{lccc} 
Parameter & Preoperative & Postoperative & Final \\
SVA $(\mathrm{mm})$ & $237.0 \pm 96.7$ & $45.3 \pm 41.8$ & $89.8 \pm 72.2$ \\
LL $\left(^{\circ}\right)$ & $10.5 \pm 14.7$ & $-40.6 \pm 10.9$ & $-34.7 \pm 15.8$ \\
\hline TK $\left(^{\circ}\right)$ & $14.7 \pm 18.0$ & $25.1 \pm 9.3$ & $32.3 \pm 13.9$ \\
PT $\left(^{\circ}\right)$ & $39.0 \pm 9.9$ & $28.7 \pm 10.1^{\text {a) }}$ & $32.8 \pm 9.1^{\text {a) }}$ \\
SS $\left(^{\circ}\right)$ & $19.3 \pm 10.2$ & $29.8 \pm 7.4$ & $25.9 \pm 8.3$ \\
\hline
\end{tabular}

SVA, sagittal vertical axis; LL, lumbar lordosis; TK, thoracic kyphosis; PT, pelvic tilt; SS, sacral slope.

All $p$-values $=0.000$ except pairing denote with ${ }^{\text {al }} p=0.001$

Table 4. Postoperative sagittal parameters and radiographic outcome stratified to osteoporosis classification

\begin{tabular}{|c|c|c|c|c|}
\hline Parameter & Osteopenia & Osteoporosis & Severe osteoporosis & $p$-value \\
\hline No. of fusion levels & $7.1 \pm 1.8$ & $6.6 \pm 1.9$ & $7.3 \pm 1.1$ & 0.521 \\
\hline Post-SVA (mm) & $40.9 \pm 34.9$ & $53.8 \pm 37.4$ & $37.3 \pm 59.3$ & 0.574 \\
\hline Post-LL $\left({ }^{\circ}\right)$ & $-43.4 \pm 10.6$ & $-38.4 \pm 10.9$ & $-39.8 \pm 11.5$ & 0.425 \\
\hline Post TK $\left({ }^{\circ}\right)$ & $26.3 \pm 7.8$ & $24.2 \pm 11.4$ & $24.7 \pm 8.3$ & 0.819 \\
\hline Post-PT $\left({ }^{\circ}\right)$ & $25.3 \pm 7.8$ & $30.2 \pm 8.1$ & $31.7 \pm 14.9$ & 0.238 \\
\hline Post-SS $\left({ }^{\circ}\right)$ & $31.7 \pm 6.1$ & $27.9 \pm 6.2$ & $29.6 \pm 10.5$ & 0.387 \\
\hline PiDiff & $14.5 \pm 11.2$ & $20.2 \pm 13.1$ & $19.5 \pm 12.7$ & 0.403 \\
\hline Final-SVA (mm) & $74.4 \pm 58.1$ & $92.8 \pm 72.9$ & $110.1 \pm 92.8$ & 0.503 \\
\hline Final LL $\left(^{0}\right)$ & $-37.5 \pm 14.7$ & $-33.1 \pm 13.1$ & $-33.0 \pm 22.1$ & 0.706 \\
\hline Final TK $\left({ }^{\circ}\right)$ & $30.6 \pm 9.1$ & $32.1 \pm 16.5$ & $35.6 \pm 16.6$ & 0.703 \\
\hline Final PT $\left({ }^{\circ}\right)$ & $33.0 \pm 2.4$ & $33.0 \pm 9.3$ & $34.6 \pm 11.3$ & 0.906 \\
\hline Final SS $\left(^{\circ}\right)$ & $26.2 \pm 8.5$ & $24.6 \pm 7.5$ & $26.7 \pm 9.9$ & 0.803 \\
\hline \multicolumn{5}{|l|}{ Complications } \\
\hline Proximal adjacent fractures & $3(20.0)$ & $1(6.3)$ & $3(33.3)$ & 0.220 \\
\hline Pseudoarthrosis & $2(13.3)$ & $1(6.3)$ & $3(33.3)$ & 0.190 \\
\hline Sagittal decompensation & $5(33.3)$ & $7(43.8)$ & $4(44.4)$ & 0.800 \\
\hline Subsidence & $1(6.7)$ & $5(31.2)$ & $2(22.2)$ & 0.220 \\
\hline
\end{tabular}

Values are presented as mean \pm standard deviation or number (\%).

SVA, sagittal vertical axis; LL, lumbar lordosis; TK, thoracic kyphosis; PT, pelvic tilt; SS, sacral slope.

$10.5^{\circ} \pm 14.7^{\circ}$ to $-40.6^{\circ} \pm 10.9^{\circ}$ immediately after the operation ( $p=0.000$, paired $t$-test). However, at the final followup, there was a statistically significant deterioration in these values. The SVA deteriorated to $89.8 \pm 72.2 \mathrm{~mm}$ and the LL to $34.7^{\circ} \pm 15.8^{\circ}$ ( $p=0.000$, paired $t$-test). These values were still significantly better then the preoperative values. When stratified according to the severity of osteoporosis, the association between osteoporosis and the amount of correction achieved or the deterioration at the final follow-up was not significant. The amount of correction obtained in the groups of patients with osteopenia, osteoporosis, and severe osteoporosis in terms of
SVA and LL during the immediate postoperative period was $40.9 \pm 34.9 \mathrm{~mm}, 53.8 \pm 37.4 \mathrm{~mm}$, and $37.3 \pm 59.3 \mathrm{~mm}$ for SVA, respectively ( $p=0.574$, one way ANOVA), and $-43.4^{\circ} \pm 10.6^{\circ},-38.4^{\circ} \pm 10.9^{\circ}$, and $-39.8^{\circ} \pm 11.5^{\circ}$ for LL, respectively ( $p=0.425$, one way ANOVA) (Table 4 ).

\section{Analysis of adverse outcomes}

Four adverse radiological outcomes were analysed; proximal adjacent fractures, sagittal decompensation, pseudoarthrosis, and cage subsidence. 


\section{1) Proximal adjacent fractures}

This adverse outcome occurred in 7 cases (17.5\%). Three cases were observed in the osteopenia group, one case in the osteoporosis group, and 3 cases in the severe osteoporosis group. Three cases underwent fusion to L1, while the upper instrumented fusion level for the remaining 4 cases was at L2, T10, T11, and T12. Minor trauma could be elicited from the history in 2 cases. The amount of correction also did not seem to have an influence on this phenomenon as the PIDiff was $16.3^{\circ} \pm 12.2^{\circ}$ in the group of patients who had proximal adjacent fractures compared with $18.2^{\circ} \pm 12.5^{\circ}$ in the group of patients who did not have proximal adjacent fractures $(p=0.718$, independent sample $t$-test). There was no statistically significant difference between the BMD in the group of patients with adjacent fractures $(-2.8 \pm 1.1)$ and that in the group of patients without adjacent fractures $(-2.8 \pm 1.2)$, with $p$-value being 0.898 (independent sample $t$-test). Two patients underwent revision with extension of the rod to a more proximal level. Pre SVA, pre LL, pre TK, pre PT, pre SS, as well as the PI in patients did not significantly influence the occurrence of proximal adjacent fractures.

\section{2) Sagittal decompensation}

This was the most common adverse outcome as it occurred in $40.0 \%$ of cases (16 patients). The SVA at the final follow-up in patients with sagittal decompensation was $164.7 \pm 50.0 \mathrm{~mm}$ compared to $39.9 \pm 26.6 \mathrm{~mm}$ in the patients without sagittal decompensation ( $p=0.000$, independent sample $t$-test). Of the 16 cases, 2 cases could be attributed to proximal adjacent fractures, 4 cases to

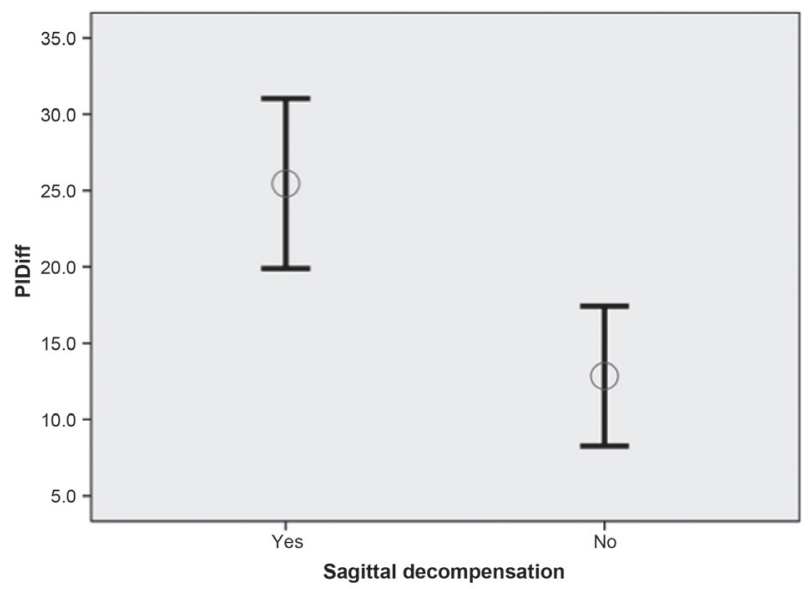

Fig. 2. Comparison between PIDiff in patients with and without sagittal decompensation. PIDiff, the difference between immediate postcorrection lumbar lordosis and the pelvic incidence. pseudoarthrosis of the fusion segment, while one case developed a proximal adjacent fracture with concomitant pseudoarthrosis of the fusion segment. As shown in Table 4 , this complication occurred in 5 patients with osteopenia, in 7 patients with osteoporosis, and in 4 patients with severe osteoporosis. This difference was not statistically significant and the $p$-value was 0.800 (chi-square test). However, the amount of correction represented by PIDiff ( $p=0.001$, independent sample $t$-test) as well as the immediate postoperative LL ( $p=0.000$, independent sample $t$-test) had a significant association with sagittal decompensation (Fig. 2). The other parameters such as pre SVA, pre LL, pre TK, pre PT, pre SS, as well as the PI in patients did not influence the occurrence of this complication.

\section{3) Pseudoarthrosis}

Pseudoarthrosis occurred in $15.0 \%$ of cases. It occurred in 2 patients with osteopenia, in 1 patient with osteoporosis, and in 3 patients with severe osteoporosis. The PIDiff was significantly different (Fig. 3) between patients who developed pseudoarthrosis $\left(26.7^{\circ} \pm 5.3^{\circ}\right)$ and patients who did not develop pseudoarthrosis $\left(16.3^{\circ} \pm 12.5^{\circ}\right)$ and the $p$-value was 0.003 (independent sample $t$-test). The preoperative sagittal parameters in patients did not significantly affect the incidence of pseudoarthrosis.

\section{4) Cage subsidence}

This adverse outcome occurred in $20.0 \%$ of cases ( 8 patients). Cage subsidence did not appear to have a significant association with sagittal decompensation $(p=0.450$, two-tailed Fisher's exact test) or pseudoarthrosis $(p=0.732$,

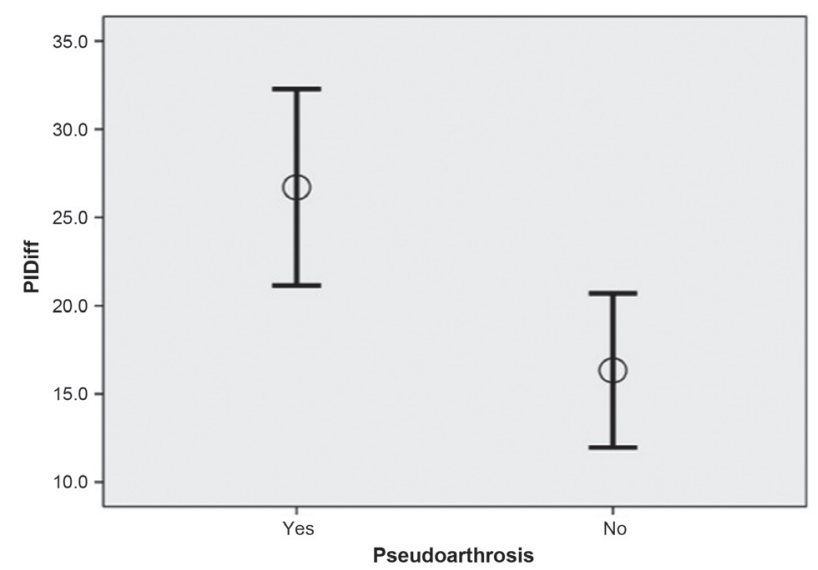

Fig. 3. Comparison between PIDiff in patients with and without pseudoarthrosis. PIDiff, the difference between immediate post-correction lumbar lordosis and the pelvic incidence. 
two-tailed Fisher's exact test). One patient with osteopenia, 5 patients with osteoporosis, and 2 patients with severe osteoporosis developed cage subsidence. The average BMD in the group with cage subsidence was $-3.5 \pm 0.7$, while the group without cage subsidence had a mean BMD of $-2.7 \pm 1.2$. This difference reached statistical significance with a $p$-value of 0.08 (independent sample $t$ test).

\section{Discussion}

In 1988, Takemitsu et al. [5] described LDK as a specific disease entity characterized by forward stooping due to progressive loss of LL. In his detailed description of this disease entity, there was a mention of various factors that lead to progressive loss of LL, which included decreased disc height, vertebral body collapse secondary to osteoporosis, and weakness of the extensor muscles of the back. The contribution of weak extensor muscles to this disease is reflected by the dynamic nature and fatigability, which patients with this disease demonstrate. Since then other authors have described morphological changes in the erector spinae muscles which is a persistent feature of this disease [14,15].

The surgical outcome for patients with LDK undergoing deformity correction has been modest. In a retrospective study of 26 patients who underwent corrective surgery, 5 patients had persistent stooping (19\%) [16]. Kim et al. [17] reported the outcome of corrective osteotomy for LDK and only $64 \%$ of patients had a good outcome in terms of pain and cosmesis. Sagittal decompensation after corrective osteotomy for LDK was introduced by Lee et al. [18]. The average amount of sagittal decompensation was $38.3 \%$, and in his series sagittal decompensation was classified into thoracic and lumbar decompensation. Sagittal decompensation due to thoracic decompensation resulted in higher degree of imbalance [18]. The ability of the patient to compensate for the imbalance preoperatively was also reported to affect the outcome [19]. To date, there have been no studies assessing the influence of bone mineral density on the outcome following corrective surgery for LDK.

As the majority of patients with LDK are elderly, the prevalence of osteoporosis could be high. Chin et al. [6] studied 1,321 patients who underwent decompression and fusion of the spine and were evaluated with DEXA scan preoperatively, and they reported that among males more than 50 years of age, $46.1 \%$ were osteopenic while $14.5 \%$ were osteoporotic. The prevalence of poor bone quality was even higher among women who were more than 50 years of age, with $41.4 \%$ of the patients having osteopenia and 51.3\% having osteoporosis [6]. These results are consistent with the results of the current study wherein $37.5 \%$ of subjects had osteopenia, $40.0 \%$ of subjects had osteoporosis, and $22.5 \%$ of subjects had severe osteoporosis.

Poor bone quality has direct influence on the pullout strength of pedicle screws. Zdeblick et al. [20] found that insertional torque of pedicle screws correlated with the bone mineral density and an insertional torque of less than 4 inch-pounds led to early pullout. Similar findings have been reported in various in vitro investigatons $[8,9,11]$. In clinical studies, Lee et al. [10] prospectively studied 181 patients undergoing spinal instrumentation and reported a positive correlation between intraoperative insertional torque of pedicle screws and the $t$ values of BMD at the instrumented level. DeWald and Stanley [7] reported on the instrumentation-related complications of multilevel fusions for adult spinal deformity in patients over 65 years of age with poor bone quality; and in their series of 38 patients, $13 \%$ had early instrumentation complications which included pedicle fractures and compression fractures while $32 \%$ had late progressive kyphosis. This complication was not preventable with instrumentation, according to the authors. Extension of fusion up to a more balanced vertebral level also did not overcome the problem. However, in this article there was no mention of the BMD in their study population [7].

The results of the current study revealed some interesting findings. Although the combination of a kyphotic lumbar spine with poor bone mineral density does not favour spinal instrumentation, the results of this study showed that low bone mineral density was not a significant factor for the amount of immediate correction, late decompensation, pseudoarthrosis, or proximal adjacent fractures. However, low bone mineral density could possibly lead to a higher incidence of cage subsidence, although this did not affect the overall outcome. This study also showed the importance of PI in determining the amount of correction needed in LDK. In previous studies, PI has been shown to be a key factor for maintaining spinopelvic harmony after correction of sagittal malalignment $[21,22]$. This parameter provides a reference for the amount of LL that needs to be restored so that sagittal 
balance can be maintained with minimal muscle activation and energy expenditure [23-25].

In LDK, the principal issue has been shown to be weakness of the extensor muscles of the lumbar spine. Therefore for maintenance of the sagittal balance, the LL should be restored as close as possible to the patient's pre-disease values. Our study confirmed that there was a significant association between PIDiff and sagittal decompensation postoperatively. The association between PIDiff and pseudoarthrosis was also significant. In patients with poor bone quality such as those in our study, several principles need to be followed to achieve adequate correction and to maintain the correction. The pedicle screws should not be used as a tool for achieving deformity correction as the purchase is compromised in the setting of poor bone quality. Adequate posterior release to increase the flexibility of the deformity coupled with anterior column support is the main method to achieve correction of the deformity. In cases wherein the deformity is more rigid, spinal osteotomies should be performed. Making the error of performing excessive rod contouring and compression of the pedicle screw construct in a stiff spine to create lordosis without adequate release will only lead to loss of purchase and loosening of the screws.

However, in this study we could not elucidate the factors that contributed to the development of proximal adjacent fractures, as the sample size for the analysis of this event was too small. We could not confirm that osteoporosis played a significant role in proximal adjacent fractures as 3 cases (42.9\%) were observed in the group with osteopenia, $1(14.3 \%)$ case was observed in the group with osteoporosis, and $42.9 \%$ of cases were observed in the group with severe osteoporosis. Results of the analysis of bone mineral density between patients with adjacent fractures and those without adjacent fractures were also not significantly different. This was in contrast with the findings of O'Leary et al. [26], and they found that the bone mineral density was lower in the group of patients who experienced failure at the top of long pedicle screw constructs.

The limitations of this study must be considered while interpreting the results. In this group of patients, none of the patients who underwent surgical correction for LDK had normal BMD values. Therefore, we did not have a 'true' control group to analyse the effect of osteoporosis on the outcome of surgical correction. Since this was a retrospective study, there could be a selection bias in the recruitment of patients. As this study was performed mainly to evaluate the effects of osteoporosis on surgical correction, our outcome measures were mainly radiological measurements as these data would reflect the feasibility and adequacy of correction in the presence of osteoporosis. However, incorporation of clinical data would make the interpretation of results more clinically relevant. The small sample size especially when stratified according to the degree of osteoporosis or the occurrence of adverse events may affect the strength of the statistical association. A longer follow-up might also help to understand more about the factors that affect the final outcome.

\section{Conclusions}

Osteoporosis in patients with LDK did not preclude good immediate correction of sagittal balance and it also did not have a significant association with late sagittal decompensation, pseudoarthrosis, or proximal adjacent fractures. The difference between immediate postoperative LL and PI was found to have a significant association with sagittal decompensation and occurrence of pseudoarthrosis.

\section{Conflict of Interest}

No potential conflict of interest relevant to this article was reported.

\section{References}

1. Lafage V, Schwab F, Skalli W, et al. Standing balance and sagittal plane spinal deformity: analysis of spinopelvic and gravity line parameters. Spine (Phila Pa 1976) 2008;33:1572-8.

2. Schwab F, Patel A, Ungar B, Farcy JP, Lafage V. Adult spinal deformity-postoperative standing imbalance: how much can you tolerate? An overview of key parameters in assessing alignment and planning corrective surgery. Spine (Phila Pa 1976) 2010;35:2224-31.

3. Jang JS, Lee SH, Kim JM, Min JH, Han KM, Maeng DH. Can patients with sagittally well-compensated lumbar degenerative kyphosis benefit from surgical treatment for intractable back pain? Neurosurgery 2009;64:115-21.

4. Glassman SD, Bridwell K, Dimar JR, Horton W, Berven S, Schwab F. The impact of positive sagittal balance in adult spinal deformity. Spine (Phila Pa 1976) 
2005;30:2024-9.

5. Takemitsu Y, Harada Y, Iwahara T, Miyamoto M, Miyatake Y. Lumbar degenerative kyphosis. Clinical, radiological and epidemiological studies. Spine (Phila Pa 1976) 1988;13:1317-26.

6. Chin DK, Park JY, Yoon YS, et al. Prevalence of osteoporosis in patients requiring spine surgery: incidence and significance of osteoporosis in spine disease. Osteoporos Int 2007;18:1219-24.

7. DeWald CJ, Stanley T. Instrumentation-related complications of multilevel fusions for adult spinal deformity patients over age 65: surgical considerations and treatment options in patients with poor bone quality. Spine (Phila Pa 1976) 2006;31:S144-51.

8. Wittenberg RH, Shea M, Swartz DE, Lee KS, White AA 3rd, Hayes WC. Importance of bone mineral density in instrumented spine fusions. Spine (Phila Pa 1976) 1991;16:647-52.

9. Soshi S, Shiba R, Kondo H, Murota K. An experimental study on transpedicular screw fixation in relation to osteoporosis of the lumbar spine. Spine (Phila Pa 1976) 1991;16:1335-41.

10. Lee JH, Lee JH, Park JW, Shin YH. The insertional torque of a pedicle screw has a positive correlation with bone mineral density in posterior lumbar pedicle screw fixation. J Bone Joint Surg Br 2012;94:93-7.

11. Halvorson TL, Kelley LA, Thomas KA, Whitecloud TS 3rd, Cook SD. Effects of bone mineral density on pedicle screw fixation. Spine (Phila $\mathrm{Pa} 1976$ ) 1994;19:2415-20.

12. Kim YJ, Bridwell KH, Lenke LG, Rhim S, Cheh G. Sagittal thoracic decompensation following long adult lumbar spinal instrumentation and fusion to L5 or S1: causes, prevalence, and risk factor analysis. Spine (Phila Pa 1976) 2006;31:2359-66.

13. Assessment of fracture risk and its application to screening for postmenopausal osteoporosis. Report of a WHO Study Group. World Health Organ Tech Rep Ser 1994;843:1-129.

14. Kang CH, Shin MJ, Kim SM, Lee SH, Lee CS. MRI of paraspinal muscles in lumbar degenerative kyphosis patients and control patients with chronic low back pain. Clin Radiol 2007;62:479-86.

15. Lee JC, Cha JG, Kim Y, Kim YI, Shin BJ. Quantitative analysis of back muscle degeneration in the patients with the degenerative lumbar flat back using a digital image analysis: comparison with the normal controls. Spine (Phila Pa 1976) 2008;33:318-25.

16. Lee CS, Lee CK, Kim YT, Hong YM, Yoo JH. Dynamic sagittal imbalance of the spine in degenerative flat back: significance of pelvic tilt in surgical treatment. Spine (Phila Pa 1976) 2001;26:2029-35.

17. Kim WJ, Kang JW, Kang SI, et al. Factors affecting clinical results after corrective osteotomy for lumbar degenerative kyphosis. Asian Spine J 2010;4:7-14.

18. Lee SH, Kim KT, Suk KS, Lee JH, Seo EM, Huh DS. Sagittal decompensation after corrective osteotomy for lumbar degenerative kyphosis: classification and risk factors. Spine (Phila Pa 1976) 2011;36:E538-44.

19. Jang JS, Lee SH, Min JH, Han KM. Lumbar degenerative kyphosis: radiologic analysis and classifications. Spine (Phila Pa 1976) 2007;32:2694-9.

20. Zdeblick TA, Kunz DN, Cooke ME, McCabe R. Pedicle screw pullout strength. Correlation with insertional torque. Spine (Phila Pa 1976) 1993;18:1673-6.

21. Rose PS, Bridwell KH, Lenke LG, et al. Role of pelvic incidence, thoracic kyphosis, and patient factors on sagittal plane correction following pedicle subtraction osteotomy. Spine (Phila Pa 1976) 2009;34:78591.

22. Lafage V, Schwab F, Patel A, Hawkinson N, Farcy JP. Pelvic tilt and truncal inclination: two key radiographic parameters in the setting of adults with spinal deformity. Spine (Phila Pa 1976) 2009;34:E599606.

23. Legaye J, Duval-Beaupere G, Hecquet J, Marty C. Pelvic incidence: a fundamental pelvic parameter for three-dimensional regulation of spinal sagittal curves. Eur Spine J 1998;7:99-103.

24. Schwab F, Lafage V, Boyce R, Skalli W, Farcy JP. Gravity line analysis in adult volunteers: age-related correlation with spinal parameters, pelvic parameters, and foot position. Spine (Phila Pa 1976) 2006;31:E959-67.

25. Vialle R, Levassor N, Rillardon L, Templier A, Skalli W, Guigui P. Radiographic analysis of the sagittal alignment and balance of the spine in asymptomatic subjects. J Bone Joint Surg Am 2005;87:260-7.

26. O'Leary PT, Bridwell KH, Lenke LG, et al. Risk factors and outcomes for catastrophic failures at the top of long pedicle screw constructs: a matched cohort analysis performed at a single center. Spine (Phila $\mathrm{Pa}$ 1976) 2009;34:2134-9. 